\title{
Experimental and numerical study on the ECARed magnesium AZ31 alloy
}

\author{
H. Hakimian, M. Sedighi And A. Asgari ${ }^{\mathrm{a}}$ \\ School of Mechanical Engineering, Iran University of Science and Technology, Tehran, Iran
}

Received 7 April 2015, Accepted 9 July 2015

\begin{abstract}
One of the best methods for applying severe plastic deformation (SPD) to the sheets is equal channel angular rolling (ECAR) process. In this paper, the effect of ECAR process on the AZ31 alloy has been evaluated. Firstly, the process has been accomplished on the magnesium specimens. Then, the effect of ECAR process on mechanical properties of AZ31 alloy such as: microhardness, strength and microstructure have been assessed. For evaluation of the ECAR parameters on the samples, numerical method also has been utilized. Finally, the results indicate that the microhardness after 8th pass ECAR has been increased about $45 \%$. Also, the average grain size has been decreased about $94 \%$ after 8 th pass ECAR. The yielding stress (Y.S) and ultimate tensile strength (UTS) of AZ31 sheet were decreased by increasing the pass number while, elongation has been improved.
\end{abstract}

Key words: ECAR / AZ31 / micro-hardness / microstructure / strength / FEM

\section{Introduction}

The magnesium alloy due to the low density $\left(1.7\right.$ g.cm $\left.{ }^{-3}\right)$ and high specific strength was specially considered by the researchers. The $\mathrm{Mg}$ alloy with HCP structure and limited slippage systems had low ductility and formability at room temperature. So the forming process on the $\mathrm{Mg}$ alloy has been accomplished at high temperature [1]. According to the requirement of lightweight materials in airplane, automobile and electrical components, the magnesium alloy has been employed. The recent research is described that grain refinements during the forming process had more effect on the mechanical properties of $\mathrm{Mg}$ alloy $[2,3]$. The AZ31 magnesium alloy (one of the most widely used magnesium alloys) due to its good strength and ductility, corrosion resistance, weldability and high strength-to-weight ratio is considered by many researchers. Also, the grain refinement behavior of the AZ31 is very attentive for improving the mechanical properties.

Severe plastic deformation (SPD) is a method for enhancement of mechanical properties and superplastic behavior with respect to the grain size reduction [4]. Equal channel angular rolling (ECAR) is a continuous SPD method that can be applied to the sheet. The schematic of the ECAR process is shown in Figure 1. So far, a

\footnotetext{
a Corresponding author:

a_asgari@mecheng.iust.ac.ir
}

few researchers have been reported on the ECAR process. For example, Chari et al. [5] presented modeling and optimization of equivalent plastic strain in equal-channel angular rolling using response surface approach. Chung et al. [6] introduced an analysis of accumulated deformation in the equal channel angular rolling process. Kvaèkaj et al. [7] pointed out the effect of several parameters on the strain and stress of ECARed sample using finite element analysis.

In the present research, the effects of the ECAR process on the mechanical properties of AZ31 alloy using both experimental and numerical approaches have been presented. Firstly, the ECAR process was accomplished on the AZ31 alloy. Then, the ECAR effects on the mechanical properties such as: microstructure, strength of materials and micro-hardness were evaluated. To assess the ECAR parameters on the equivalent strain, finite element analysis as an effective tool has been utilized. Finally the experimental and numerical results have been analyzed.

\section{Experimental procedure}

The AZ31 magnesium alloy sheets with size of $180 \mathrm{~mm}$ $\times 20 \mathrm{~mm} \times 2 \mathrm{~mm}$ (length $\times$ width $\times$ thickness) were used as an initial material. The chemical composition of the materials has been shown in Table 1. The prepared samples were fed into the rolling machine with diameter of 


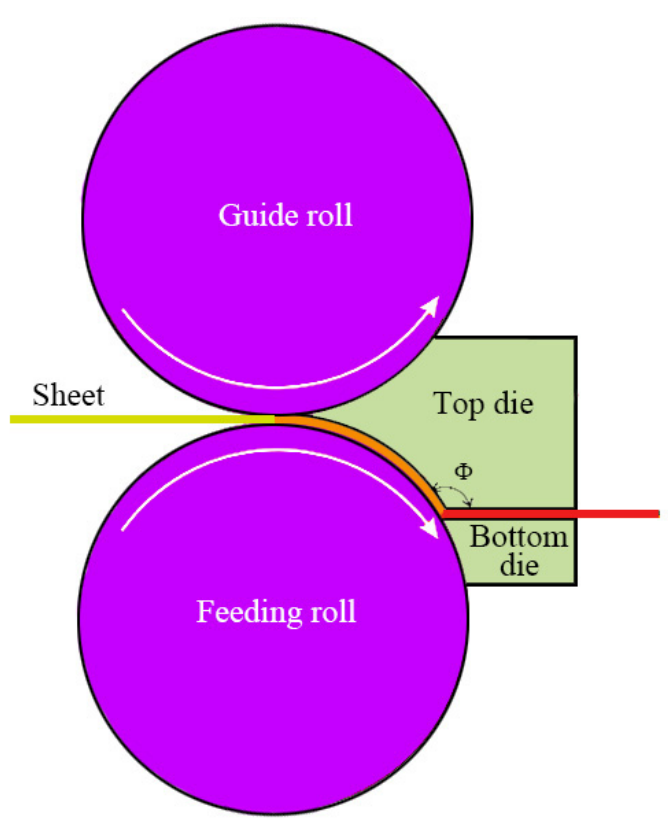

Fig. 1. The schematic of the ECAR process.

Table 1. The chemical composition of the AZ31 magnesium alloy $(\%)$.

\begin{tabular}{ccccccc}
\hline $\mathrm{Mg}$ & $\mathrm{Al}$ & $\mathrm{Zn}$ & $\mathrm{Mn}$ & $\mathrm{Si}$ & $\mathrm{Fe}$ & $\mathrm{Cu}$ \\
\hline 95.557 & 3.035 & 1.138 & 0.208 & 0.031 & 0.003 & 0.029 \\
\hline
\end{tabular}

$241 \mathrm{~mm}$ that equipped by ECAR die. The inlet and outlet channel thickness were $1.95 \mathrm{~mm}$ and $2 \mathrm{~mm}$, respectively. The curved top die of ECAR device had angle of $120^{\circ}$ with bottom die. After each pass, the sample was rotated $180^{\circ}$ around its longitudinal axis. Due to the low formability of the magnesium sheet at room temperature and high shear strain of the ECAR process, the samples were preheated before each pass for $4 \mathrm{~min}$. At about $0.5 T_{\mathrm{m}}$ (melting temperature), dynamic recrystallization (DRX) phenomenon is usually occurred. Tan and Tan [8] studied the domination of continuous recrystallization phenomena on AZ31 in the range of 523-673 K. They reported that the grain refinement during DRX is insignificant at high temperatures due to the rapid grain growth. The initial temperature of the present work has been chosen based on the suggestion by Fatemi-Varzaneh et al. [9]. The preheating procedure of the samples is as follows: the first pass of ECAR process was applied to the sheet at $620 \mathrm{~K}$. Then, the process temperature was decreased about $20 \mathrm{~K}$ in each pass for better grain refinement. In fact, to maximize the grain-refining effect with minimizing the cracking, the ECAP temperature was chosen to be high initially and then lowered with pass number [10]. The view of experiments is shown in Figure 2.

To evaluate the effects of pass number on the microstructure, ECARed samples after polishing process were etched at room temperature using a solution of $10 \mathrm{ml}$ acetic acid, $4.2 \mathrm{~g}$ picric acid, $10 \mathrm{ml} \mathrm{H} 2 \mathrm{O}$ and $70 \mathrm{ml}$ ethanol [11]. The changed microstructure of the ECARed sheets was examined using optical microscopy and scan-

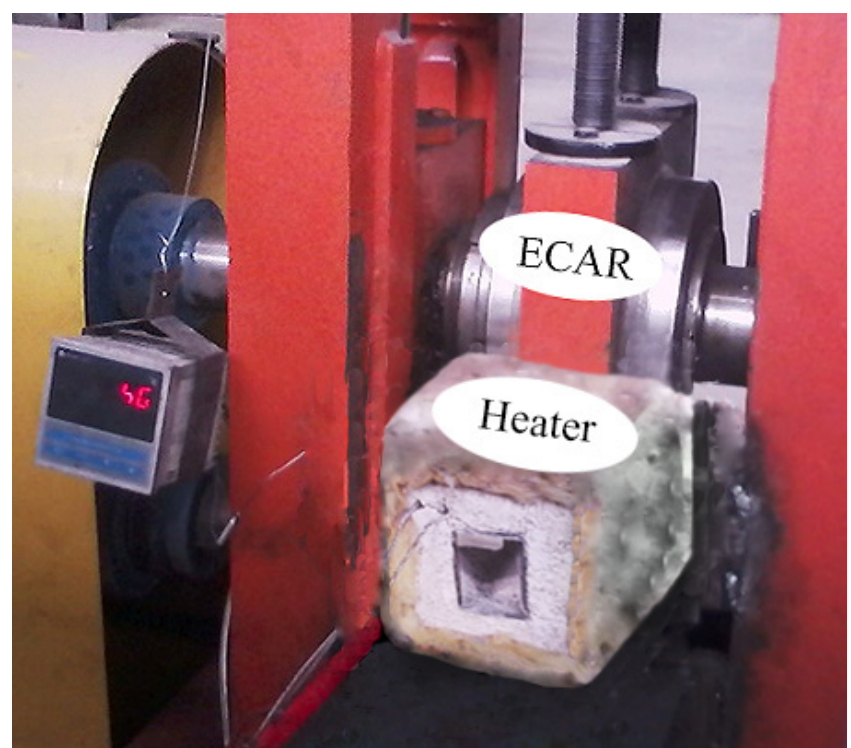

Fig. 2. The view of experimental devices for AZ31 ECAR process.

ning electron microscopy (SEM). For analysis of the material strength after ECAR process, uniaxial tensile test was used. Also, the averaging of micro-hardness $(\mathrm{Hv})$ in 3 points on each sample was measured by applying a load of $100 \mathrm{~g}$ for $5 \mathrm{~s}$.

\section{Numerical method}

One of the best methods for evaluation of any process is finite element method (FEM) that leads to reduction of costs in comparison with physical modeling. In this study, the ECAR process was simulated by Abaqus-V6.12 software. The schematic of the simulated ECAR process has been shown in Figure 3. The magnesium sheet, rollers and dies dimensions were simulated based on the values of experimental conditions. The simulation conditions are divided into 3 important sections as following: (1) Parts and geometrical dimensions; (2) material properties; and (3) selected mesh. Firstly, the 2D deformable planar part has been selected as a sample modeling due to the planestrain assumption of the process. The rollers and dies were assumed to be rigid. Then, material properties of AZ31 alloy were applied to the model. After mesh sensitivity analysis (MSA) as a routine process (with acceptable error of $4 \%$ ), the deformed sample was divided into 8000 elements of CPE4R. The initial data for simulation of the process have been presented in Table 1 .

\section{Results and discussion}

\subsection{Microstructure}

The microstructure of the as-received materials and ECARed AZ31 alloy sheet in several passes is shown in 


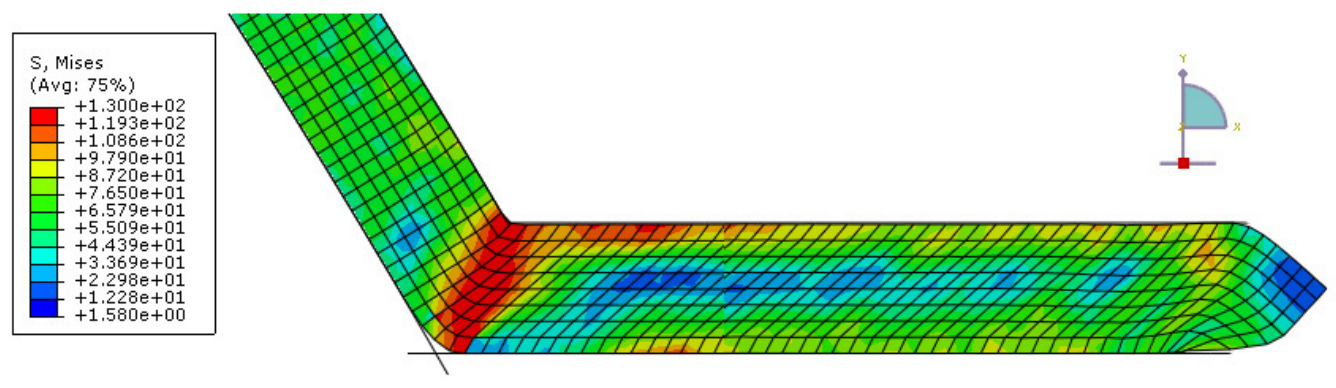

Fig. 3. The simulation view of ECAR process.

Table 2. Initial data for numerical method.

\begin{tabular}{cc}
\hline \multicolumn{2}{c}{ Geometrical data } \\
\hline Roll diameter & $241 \mathrm{~mm}$ \\
Die channel angle & $120 \mathrm{degree}$ \\
Sheets dimension & $180 \mathrm{~mm} \times 20 \mathrm{~mm} \times 2 \mathrm{~mm}$ \\
\hline Materials behavior & $1.7 \mathrm{~g} . \mathrm{cm}^{-3}$ \\
Density & $29 \mathrm{GPa}$ \\
Young modulus & 0.23 \\
Poisson ratio & $70 \mathrm{MPa}$ \\
Yielding stress & $110 \mathrm{MPa}$ \\
Ultimate stress & \\
\hline Simulation data & $1.9 \mathrm{rad} . \mathrm{s}^{-1}$ \\
\hline Angular velocity of the roll & 0.4 \\
Friction coefficient between roller and sheet & 0.12 \\
Friction coefficient between channel die and sheet
\end{tabular}

Figure 4. As seen in the figure, the annealed microstructure was not homogeneous. Also, mixed grains with the fine and coarse grains were placed on the as-received sample and the average grain size was about $23 \mu \mathrm{m}$. The grain size was reduced and uniformed by increasing the pass number of ECAR.

General deformation mechanisms in the materials with an HCP structure like magnesium are twinning and dynamic recrystallization [12]. In dynamic recrystallization, as opposed to static recrystallization, the nucleation and growth of new grains occur during deformation rather than afterwards as part of a separate heat treatment [13].

Uniform and homogeneous structure could be due to high shear strain that was applied to the sample during the process. Due to the high temperature of preheating, by increasing the pass number from 1 to 3, the average grain size was changed slightly. But after 3th pass, the grains have been refined and significant reduction in grain size was observed. The DRX was the reason of grain size reduction after 3 th pass due to the low recrystallization temperature of magnesium alloy. In fact, the severe plastic deformation at high strain rate during ECAR process leads to the conversion of partial mechanical work to the heat [14]. On the other side, the amount of strain can affect the DRX phenomenon by itself. The SEM micrographs of ECARed specimen after 1 and 8 passes are shown in Figure 5.
As seen in Figure 5a, the twinning can be observed after 1 pass ECAR process on the magnesium sheet. The small grain formation with the average grain size of 200$500 \mathrm{~nm}$ on the coarse grains boundary was observed in Figure 5b. In fact, this phenomenon can be attributed to the effect of DRX [15]. In general, the average grain size after 8 th pass was decreased about $1 \mu \mathrm{m}$.

\subsection{Strength of materials}

For evaluation of the ECAR effect on the strength of magnesium alloy sheet, uniaxial tensile test has been utilized. The results of the tensile test for AZ31 specimens versus pass numbers have been shown in Figure 6 .

After ECAR process, samples drawbility has been improved compared to the as-received materials. The yielding stress (Y.S) and ultimate tensile strength (UTS) of AZ31 sheet were decreased by increasing the pass number. The elongation of as-received materials was changed from $9 \%$ to $17 \%$ after 1 pass ECAR process, but elongation has been decreased for the other passes. In fact, the material elongation has been improved after ECAR process.

In general, the variation of elongation for magnesium is related to the average grain size and structure. In spite of grain refinement for AZ31 alloy after ECAR process, yielding stress was decreased while elongation was improved. These two events could be attributed due to the 


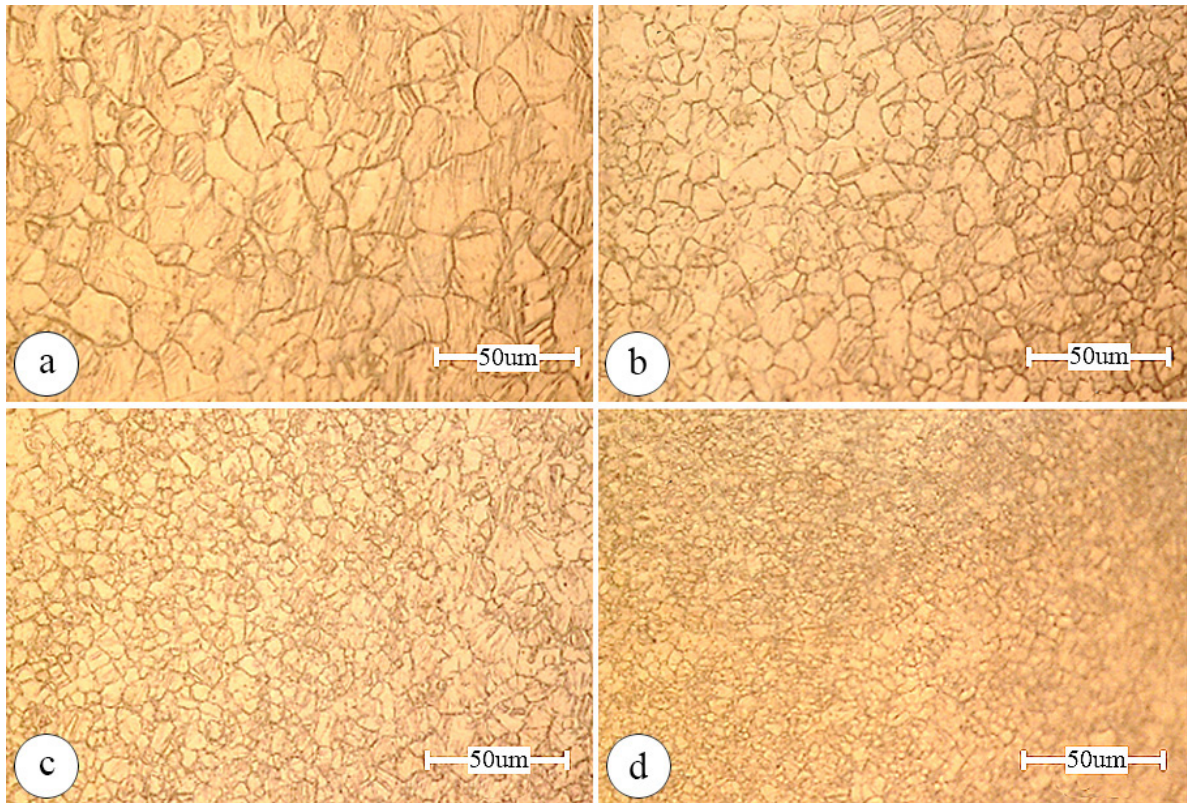

Fig. 4. The micrographs of ECARed AZ31 samples, (a) annealed, (b) $1^{\text {st }}$ pass, (c) $5^{\text {th }}$ pass and (d) $8^{\text {th }}$ pass.

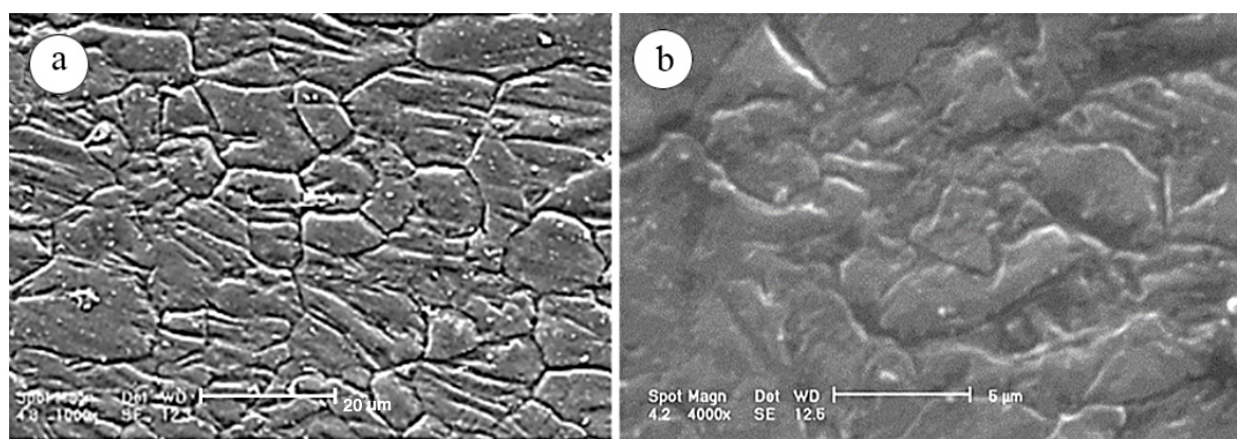

Fig. 5. The SEM micrographs of ECARed sheets, (a) After 1 pass and (b) After 8 passes.
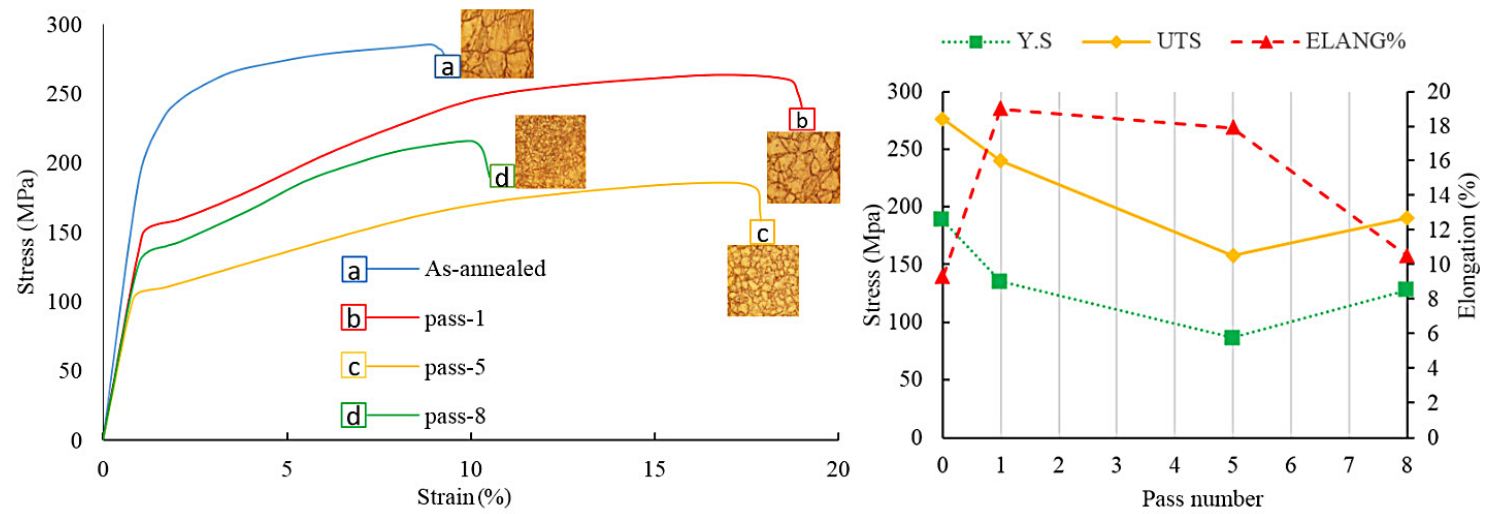

Fig. 6. Nominal stres-strain curves of the as-received and ECARed samples. 


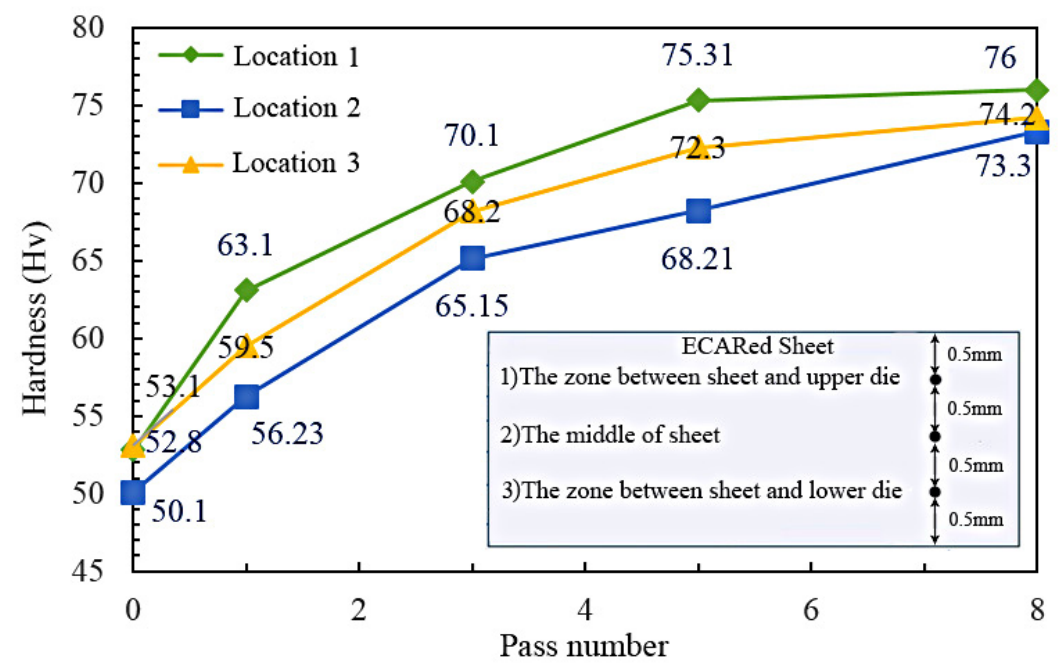

Fig. 7. The variation of hardness in 3 locations.

structure improvement during the ECAR process. The change in structure during the ECAR process was led to rotation of basal planes and activation of non-basal slip systems as Well [16]. As a result, due to the process, yielding stress, elongation and toughness were increased. Increasing in the temperature leads to the reduction of dislocation density and as a result, yielding stress was decreased and elongation was increased. Increasing in the strength and elongation for 8 th pass compared to the 5 th pass could be attributed to the presence of the large number of twinnings and low preheating for 8th pass. The low preheating in 8 th pass could not remove the previous twinnings and leads to the higher work hardening. Also, twinning boundary is a strong barrier against of dislocation slip [17]. So, twinning boundary leads to increasing in strength similar to grain boundary.

\subsection{Microhardness}

The Vickers microhardness measurement of the AZ31 alloy has been presented in the Figure 7. As seen, the hardness $(\mathrm{Hv})$ gradually was increased so that after 8th pass had maximum value. In fact, in the initial stage of ECAR process, strain hardening is the predominant mechanism. Then, by increasing the pass number, finegrained material with grater total boundaries were observed that leads to prevent the movement of dislocations and the hardness was increased. So, the hardness was increased by decreasing the grain size and increasing the pass number. Finally, due to saturation of the accumulated strain in higher passes, the hardness value was changed. The hardness after 8 th pass was increased about $45 \%$.

According to Figure 7, the hardness in the zone between sheet and upper die was higher than for the middle of sheet. The hardness for higher passes due to the grains uniformity in 3 locations was near together.

\subsection{Numerical analysis}

The imposed strain in dissimilar channel angular pressing (DCAP) process was calculated by Lee et al. [18] as following:

$$
\varepsilon=\frac{K^{2} 2 N}{\sqrt{3}} \cot \frac{\phi}{2}
$$

where $K$ is the thickness ratio, $N$ is the number of passes and $\phi$ is die channel angle. Furthermore, Lee et al. [18] calculated the shear strain that imposed to the sheet during ECAR process:

$$
\gamma=K^{2}\left[2 \cot \left(\frac{\phi+\psi}{2}\right)+\psi \operatorname{cosec}\left(\frac{\phi+\psi}{2}\right)\right]
$$

where $\gamma$ is the shear strain, $K$ thickness ratio, $\phi$ die angle channel angle and $\psi$ is die outer corner angle. The validation between Lie formula and FEM approach is shown in Figure 8.

According to the figure, the inclination angle was obtained at 42.3 degrees, which gives the value of shear strain as $\gamma=\tan (441)=0.97$. This shear strain value had good accordance with relation $2(\gamma=1.09)$.

\subsubsection{Effect of die angle on the strain}

The effect of die angle on the strain is shown in Figure 9. As seen, by reduction of die angle, the imposed shear strain to the sample was increased and the materials were covered the corner of die.

According to the Figure 9, the equivalent strain has increased about $50 \%$ by decreasing the die angle from 120 to 90 degree. Also, the effective strain on the bottom of ECARed sample was increased by decreasing the die angle. In fact, due to the clashing between outlet die and specimen in the lower die angle, the strain was increased and accumulated on the bottom of the sample. 


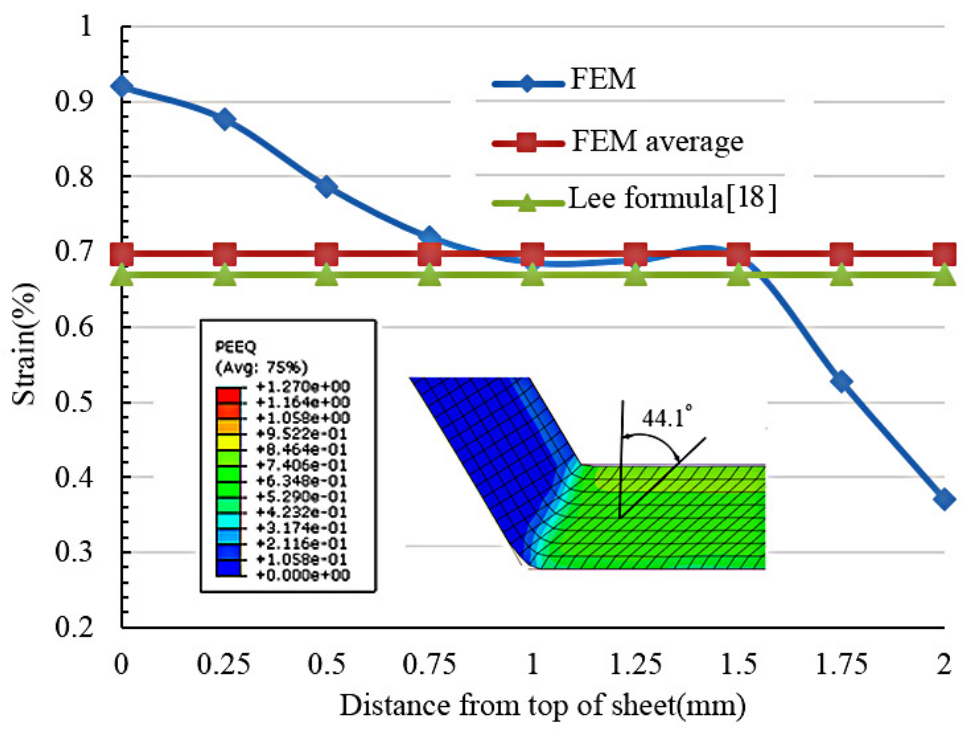

Fig. 8. Validation of FEM approach.

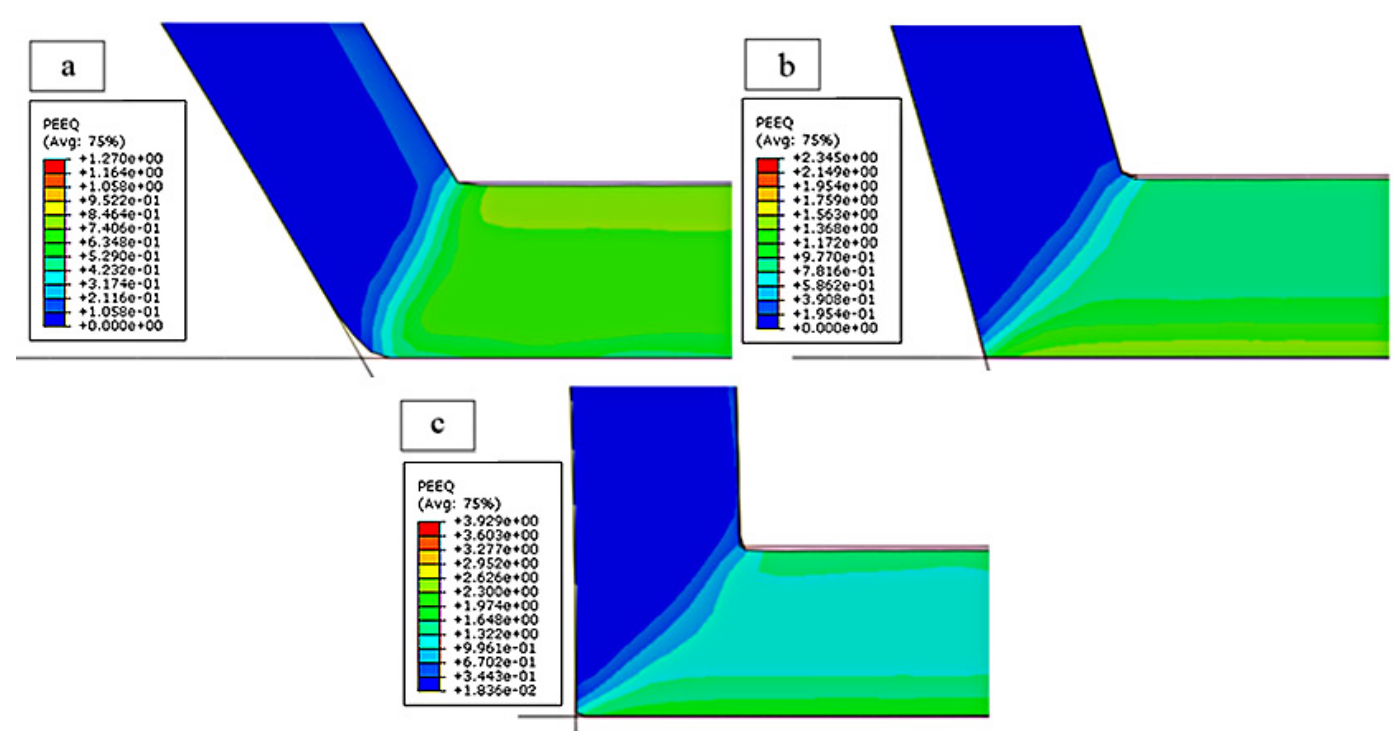

Fig. 9. Effect of die angle on the strain, (a) Die angle of $120^{\circ}$, (b) Die angle of $105^{\circ}$ and (c) Die angle of $90^{\circ}$.

\subsubsection{Effect of friction coefficient on the effective strain}

To assess the friction coefficient effect on the imposed strain (for lubrication condition) three values of $0.14,0.17$ and 0.21 has been considered $[5,19]$. These effects are shown in Figure 10.

As seen, the equivalent strain has been increased about $30 \%$ by increasing the friction coefficient from 0.14 to 0.21 . Also, the strain homogeneity in high friction coefficient was increased due to the higher effects of channel on the sample during the process. So that, the corner of die was filled by materials for higher friction coefficient. In fact, due to the continuous increase in the contact between sample and die in exit channel, frictional drag has been occurred in the exit channel. This works like a back pressure and the corner of gap has been filled [19].

\section{Conclusion}

In this paper, equal channel angular rolling process was performed on the AZ31 magnesium alloy sheet using experimental and numerical method. According to the research, the following results are drawn:

- The ECAR process at high temperature was an appropriate process for grain refinement of AZ31 alloy.

- The grain uniformity was increased by increasing the pass number of ECAR process.

- The average grain size after 8th pass ECAR was reduced about $94 \%$ and the average grain size of about $1 \mu \mathrm{m}$ was achieved. Also, the grain with size of $200-$ $500 \mathrm{~nm}$ was observed at the boundary of coarse grains.

- The Vickers microhardness after 8th pass ECAR has been increased about $45 \%$. 


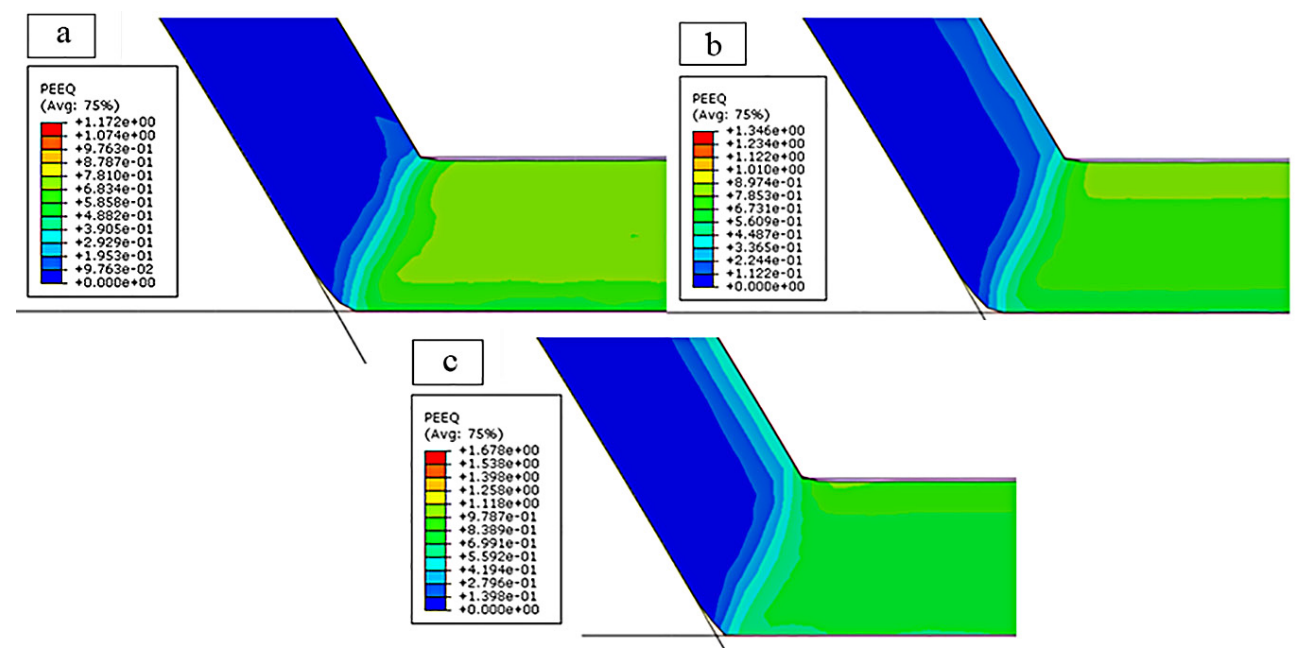

Fig. 10. Effect of friction coefficient on the strain, (a) $\mu=0.14$, (b) $\mu=0.17$ and (c) $\mu=0.21$.

- The yielding stress (Y.S) and ultimate tensile strength (UTS) of AZ31 sheet were decreased by increasing the pass number while elongation has been improved.

- According to the FEM approach, the equivalent strain of ECARed sample increased about $50 \%$ by decreasing the die angle from 120 to 90 degrees

- The equivalent strain increased about $30 \%$ by increasing the friction coefficient from 0.14 to 0.21 .

\section{References}

[1] T.C. Chang, J.Y. Wang, C. Ming, S. Lee, Grain refining of magnesium alloy AZ31 by rolling, J. Mater. Process. Technol. 140 (2003) 588-591

[2] H.K. Kim, The grain size dependence of flow stress in an ECAPed AZ31 Mg alloy with a constant texture, J. Mater. Sci. Eng. A 515 (2009) 66-70

[3] G.B. Hamu, D. Eliezer, L. Wagner, The relation between severe plastic deformation microstructure and corrosion behavior of AZ31 magnesium alloy, J. Alloys Compd. 468 (2009) 222-229

[4] R. Jahedi, M. Sedighi, H. Jahed, ECAP effect on the micro-structure and mechanical properties of AM30 magnesium alloy, J. Mater. Sci. Eng. A 593 (2014) 178-184

[5] R.N. Chari, A. Kami, B.M. Dariani, Modeling and optimization of equivalent plastic strain in equal-channel angular rolling using response surface methodology, J. Eng. Manuf. (2014) DOI: 10.1177/0954405414542855

[6] Y.H. Chung, J.W. Park, K.H. Lee, An analysis of accumulated deformation in the equal channel angular rolling(ECAR) process, J. Metals Mater. Int. 12 (2006) 289-292

[7] M. Kvaèkaj, T. Kvaèkaj, A. Kováèová, R. Koèiško, J. Bacsó, Finite element analysis of deformation behavior in equal channel angular rolling process, Acta Metallurgica Slovaca 16 (2010) 84-90

[8] J.C. Tan, M.J. Tan, Dynamic continuous recrystallization characteristics in two stage deformation of $\mathrm{Mg}-3 \mathrm{Al}-1 \mathrm{Zn}$ alloy sheet, J. Mater. Sci. Eng. A 339 (2003) 124-132
[9] S.M. Fatemi-Varzaneh, A. Zarei-Hanzaki, H. Beladi, Dynamic recrystallization in AZ31 magnesium alloy, J. Mater. Sci. Eng. A 456 (2007) 52-57

[10] H.K. Kim, W.J. Kim, Microstructural instability and strength of an AZ31 Mg alloy after severe plastic deformation, J. Mater. Sci. Eng. A 385 (2004) 300-308

[11] K. Xia, J.T. Wang, X. Wu, G. Chen, M. Gurvan, Equal channel angular pressing of magnesium AZ31 alloy, J. Mater. Sci. Eng. A 410 (2005) 324-327

[12] H.Q. Sun, Y.N. Shi, M.X. Zhang, K. Lu, Plastic straininduced grain refinement in the nanometer scale in a $\mathrm{Mg}$ alloy, Acta Mater. 55 (2007) 975-982

[13] F.J. Humphreys, M. Hatherly, Recrystallization and Related Annealing Phenomena, 2nd edition, Elsevier, 2004

[14] M. Aibin, J. Jiang, N. Saito, I. Shigematso, Y. Yuan, D. Yang, Y. Nishida, Improving both strength and ductility of a $\mathrm{Mg}$ alloy through a large number of ECAP passes, J. Mater. Sci. Eng. A 513 (2009) 122-127

[15] C. Chang, X.H. Du, J.C. Huang, Producing Nano grained microstructure in $\mathrm{Mg}-\mathrm{Al}-\mathrm{Zn}$ alloy by two-step friction stir processing, Scri. Mater. 59 (2008) 356-359

[16] H. Watanabe, M. Toshiji, I. Koichi, Effect of temperature of differential speed rolling on room temperature mechanical properties and texture in an AZ31 magnesium alloy, J. Mater. Process. Technol. 182 (2007) 644-647

[17] C.X. Huang, G. Yang, Y.L. Gao, S.D. Wu, Z.F. Zhang, Influence of processing temperature on the microstructures and tensile properties of 304L stainless steel by ECAP, J. Mater. Sci. Eng. A 485 (2008) 643-650

[18] J.C. Lee, H.K. Seok, J.Y. Suh, Microstructural evolutions of the $\mathrm{Al}$ strip prepared by cold rolling and continuous equal channel angular pressing, Acta Materialia 50 (2002) 4005-4019

[19] B.V. Patil, U. Chakkingal, P.T. S Kumar, Influence of friction in equal channel angular pressing - A study with simulation, In international Conference on Metallurgy and Materials, 2008, pp. 1-9 